\title{
Whale deaths caused by US Navy's sonar
}

\section{Mark Schrope}

The US Navy has admitted that its use of a high-intensity sonar system caused a rash of whale strandings and deaths in March 2000.

Sixteen beaked and minke whales were found stranded on beaches in the Bahamas shortly after US Navy ships using the highintensity sonar had passed by. Six are known to have died, and the rest were pushed back into the sea. But a fall in sightings of beaked whales has led researchers working in the area to believe that many more may have died. Autopsies on the animals revealed bleeding around the whales' inner ears and in one instance in the brain.

The Navy and the National Marine Fisheries Service (NMFS) responded to the incident by launching a series of investigations. An interim synopsis of the reports, released on 20 December 2001, concludes that the bleeding was caused by sound waves produced by the high-intensity sonar.

The synopsis was welcomed by environmental groups, which claim that highintensity sonar may have caused other strandings. Autopsy evidence in previous

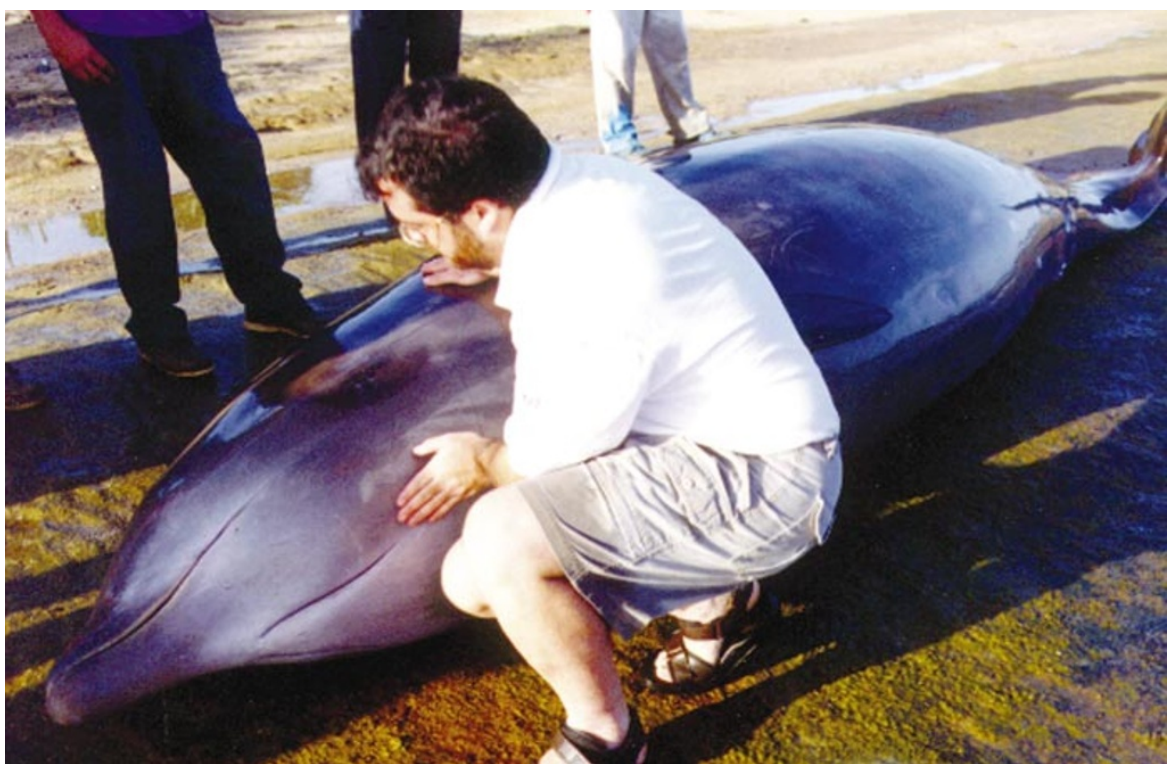

High and dry: the US Navy's use of high-intensity sonar left whales on the beach in the Bahamas.

cases could not identify the cause of the stranding. "This is the first time the Navy has really acknowledged responsibility for

\section{NIH faces action over HIV cat study}

\section{Erika Check, Washington}

The US National Institutes of Health (NIH) is being sued over a research project that involves giving amphetamines to cats infected with the feline equivalent of HIV.

The Physicians Committee for Responsible Medicine (PCRM), a Washington-based pressure group that opposes animal experiments and advocates preventative health care, launched the action on 27 December. Using the Freedom of Information Act, it wants to force the NIH to release all the documents relating to the grant proposal made for the project.

The study is led by Michael Podell, a

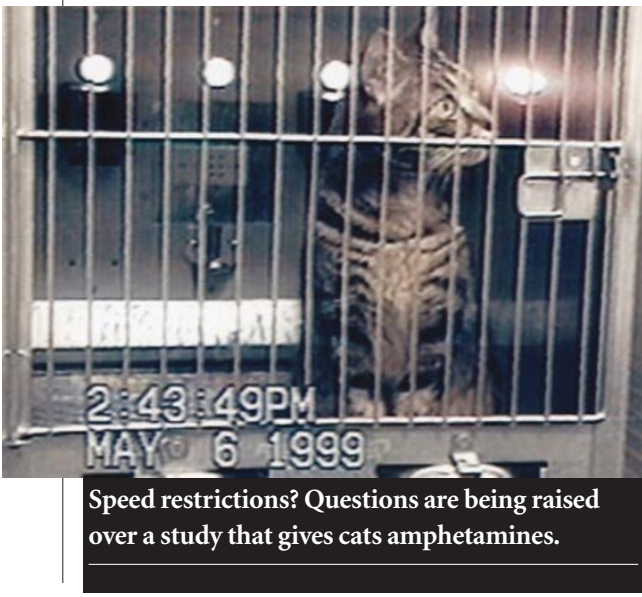

veterinarian at Ohio State University in Columbus, who is investigating the interactions between drug abuse and AIDS.

Podell won a five-year grant worth $\$ 1.7$ million from the National Institute on Drug Abuse, part of the NIH, in autumn 2000 to study neurological changes in cats infected with feline immunodeficiency virus (FIV) and exposed to high doses of methamphetamine, the recreational drug more commonly known as speed.

The PCRM claims that the study is cruel and scientifically unnecessary, and wants the NIH to release more information about the project, including the outcome of Podell's pilot studies.

Podell, the NIH and Ohio State University have each declined to comment on the lawsuit. But in a previous statement, Podell said that his feline study will help to establish how HIV and drug abuse cause brain damage in human patients.

Murry Cohen, a psychiatrist affiliated with the PCRM, says that the feline model is too dissimilar from the human infection to yield clinically relevant information.

But Dennis Kolson, a neurologist at the University of Pennsylvania, says: "There are so few in vivo model systems for retroviral diseases like HIV that we have to utilize each one to its fullest extent, and the FIV system fits into that, as does the primate model." anything like this," says Andrew Wetzler of the National Resources Defense Council, a New York-based environmental group.

But the report says that the high-intensity sonar may not pose a widespread threat to marine life. Such systems are commonly used, and the synopsis says the strandings were the result of unique local conditions. The sound waves were trapped in a layer of warm water, preventing their dissipation, and the whales could not escape because they were feeding in underwater canyons.

But according to Roger Gentry, coordinator of the NMFS acoustics team, the possibility that other conditions might cause similar problems cannot be ruled out, as it is not understood how the sound waves caused the bleeding. Several US research groups are looking into this issue.

Although he welcomes the report, Wetzler claims that the Navy is playing down the importance of its conclusions by focusing on unique characteristics of the event. "We really believe that this is an important piece of evidence that calls for all parties to re-examine all use of high-intensity sonar around the globe," he says.

The report comes at a sensitive time. The US Navy is seeking approval for a new highintensity sonar system (see Nature 410, 505; 2001). The system, which operates at lower frequencies than that responsible for the Bahamas strandings, is needed to detect new, quieter submarines, the Navy says. The NMFS will have to approve use of the system under the Marine Mammal Protection Act, and Gentry says a decision should be made within a few months. But he says the report is unlikely to significantly affect the approval process.

www.nmfs.noaa.gov 